\title{
Socialização legal de crianças e adolescentes: revisão da literatura e desafios de pesquisa
}

\author{
Legal socialization of children and adolescents: literature \\ review and research challenges
}

\section{Herbert Rodrigues ${ }^{a}$, Aline Morais Mizutani Gomes ${ }^{b}$, Renan Theodoro de Oliveirac, Debora Piccirillod e Rafael Cardoso de Brito}

\begin{abstract}
Resumo Este artigo visa apresentar a socialização legal como um campo de investigação que busca compreender a maneira pela qual as crianças e os adolescentes desenvolvem suas noções sobre autoridades, regras e leis. Trata-se de uma revisão da literatura dividida em dois segmentos centrais: um balanço teórico das chamadas abordagens tradicionais e uma síntese dos estudos recentes sobre a temática da socialização legal. Além disso, o artigo sinaliza alguns desafios de pesquisa que podem contribuir para o entendimento desse processo no contexto brasileiro.
\end{abstract}

Palavras-chave Socialização legal; Legitimidade; Autoridade; Justiça procedimental; Adolescentes

\begin{abstract}
The article aims to present the legal socialization as an inquiry field that seeks to understand how children and adolescents develop their views on authorities, rules and laws. This article presents a literature review divided into two main segments: a theoretical review about the traditional approaches and a brief review about the recent studies on the legal socialization. In addition, the article indicates some research challenges that can contribute to the understanding of this process in the Brazilian context.
\end{abstract}

Keywords Legal socialization; Legitimacy; Authority; Procedural justice;

Adolescents

a Doutor em Sociologia pela Universidade de São Paulo (USP) e mestre em Antropologia Social pela Universidade de São Paulo (USP). Foi Visiting Scholar da University of Massachusetts (UMASS/Amherst). É pesquisador do Núcleo de Estudos da Violência da Universidade de São Paulo (NEV-USP)

b Mestre em Psicologia Escolar pela Universidade de São Paulo. É pesquisadora do Núcleo de Estudos da Violência da Universidade de São Paulo (NEV-USP).

c Mestre em Sociologia pela Universidade de São Paulo. É pesquisador do Núcleo de Estudos da Violência da Universidade de São Paulo (NEV-USP).

d Bacharel em Ciências Sociais pela Universidade de São Paulo. É pesquisadora do Núcleo de Estudos da Violência da Universidade de São Paulo (NEV-USP).

e Graduando em Psicologia pela Universidade Presbiteriana Mackenzie. É pesquisador do Núcleo de Estudos da Violência da Universidade de São Paulo (NEV-USP). 


\section{INTRODUÇÃO}

A socialização é um tema fundamental das ciências sociais. Pode-se afirmar que a compreensão desse processo está presente desde a formação da sociologia como disciplina autônoma, responsável pela explicação da vida social. A socialização é a aquisição de valores, de hábitos e de normas. Mas não somente. À primeira vista, a internalização de regras remete à ideia de passividade do indivíduo em relação ao grupo social. No entanto, trata-se de processo relacional marcado pelo desvencilhamento do indivíduo das determinações da sociedade a partir das experiências estabelecidas ao longo da vida.

A socialização está relacionada ao processo de aprendizagem por meio do qual os indivíduos, ainda crianças, adquirem os valores de determinada sociedade. Algumas abordagens teóricas dividem esse processo entre dois tipos: primário e secundário. Por um lado, a socialização primária remete à tarefa da família em transmitir, via laços consanguíneos e afetivos, os ensinamentos básicos necessários para a vida (acesso inicial à linguagem, às regras morais, aos modelos de comportamento). Por outro lado, a socialização secundária ocorre pelo processo educativo, principalmente por meio da escola e da figura do professor.

Uma formulação durkheimiana clássica sintetiza bem esse raciocínio: a educação é o instrumento que a geração adulta utiliza para socializar a geração mais jovem. À medida que esse processo se torna eficaz, melhor será o ajuste dos indivíduos à sociedade. Há ainda outras perspectivas que incluem a igreja, $o$ trabalho, os grupos de pares e amigos, e as relações por identidade, como componentes vinculados ao processo de socialização.

Reconhecemos que a discussão genérica acerca da socialização e o debate em torno do processo de aprendizagem já estão consolidados nas ciências sociais, por isso esses temas não serão retomados neste artigo. O objetivo aqui é o de apresentar um importante desdobramento desse campo de problematização denominado socialização legal, que é o processo pelo qual os indivíduos formam noções sobre as leis, as autoridades e as instituições legais.

A socialização legal requer atenção para dois processos distintos, porém interligados: a internalização das normas sociais que controlam o comportamento e o desenvolvimento de valores morais que orientam as condutas de obediência às autoridades. O primeiro processo se mostra importante porque ao internalizar as normas da sociedade os indivíduos tendem a inibir comportamentos socialmente inaceitáveis e a reforçar comportamentos desejáveis; os indivíduos não só desenvolvem seus próprios sentidos de "certo" e "errado" como passam a entender os valores sociais apropriados do meio no qual estão inseridos (TrinkNeR; CoHN, 2014). 
O segundo processo é moldado pelo contato com as autoridades, possibilitando ao indivíduo desenvolver o senso de dever de obediência consentida para com as regras e as decisões tomadas pelas autoridades e as instituições democráticas (FAgAn; Tyler, 2005).

No contexto norte-americano, há algumas décadas, a psicologia social e a criminologia destinam bastante atenção ao estudo da socialização legal e desenvolvem pesquisas que procuram compreender as atitudes e comportamentos legais (Cohn; White, 1990), as interações com figuras de autoridade que geram percepções de justiça (FAGAN; Tyler, 2005), o comportamento de quebra de regras e as percepções sobre as autoridades (TRINKNER, 2012), a relação entre socialização legal e agressão relacional (JELENIEWISK, 2014), o impacto do cinismo legal na conduta dos indivíduos (Trinkner; CoHn, 2014), entre outros.

Contudo, acreditamos que algumas lacunas teóricas permanecem abertas e questões importantes no âmbito da socialização legal ainda carecem de elucidações, especialmente no Brasil, onde esses estudos ainda são pouco explorados.

A relação das crianças e adolescentes brasileiros com as normas, as leis e as autoridades é tratada por diferentes disciplinas e pode-se encontrar extensa literatura sobre delinquência juvenil tanto no campo de estudos da violência e da psicologia quanto da educação e saúde pública. Nota-se que o foco está nos adolescentes em conflito com a lei, de modo que outras possibilidades de compreensão da relação com o universo legal, as autoridades e as instituições tendem a ficar de fora da maioria dos estudos. Daí a importância de trazer essa discussão para o contexto brasileiro e apontar alguns desafios de pesquisa no âmbito da sociologia.

Historicamente, o campo da socialização legal foi dominado por duas abordagens, que chamaremos para fim de exposição de "tradicionais": a cognitivista, embasada na ideia de que os indivíduos, por meio do processo de maturação, desenvolvem habilidades cognitivas cada vez mais complexas que moldam as percepções e interpretações sobre normas e leis (TAPP; KoHLBERG, 1971; LEvinE; TAPP, 1974); e a da aprendizagem social, que preza pelo condicionamento do comportamento através de estímulos ambientais (ARONFrEED, 1968 BANDURA, 1969).

Mais recentemente, o campo da socialização legal avançou em direção aos estudos sobre a legitimidade das autoridades e das instituições. Partindo da premissa de que o respeito às leis depende da aceitação das decisões das autoridades, observar o processo pelo qual os indivíduos legitimam as instituições se mostrou indispensável para a compreensão dos comportamentos e atitudes das crianças e dos adolescentes em relação ao mundo legal. Assim, esses estudos passaram a observar o vínculo entre o processo de socialização legal e a atribuição 
de legitimidade ou não às autoridades, baseando-se principalmente em abordagens ancoradas na teoria da justiça procedimental (procedural justice) com foco na juventude (Piquero et al., 2005; TYler et al., 2014; Trinkner; CoHn, 2014; Trinkner; TYLER, 2016).

Antes de iniciar a exposição sobre as abordagens tradicionais e os estudos recentes, é importante ressaltar que a socialização legal é um campo amplo de investigação e não uma teoria social restrita. Como apontam Cohn e Modecki (2008), não existe consenso estabelecido baseado em medições matemáticas. Trata-se, acima de tudo, de um conjunto de pesquisas que possibilitam inúmeras abordagens do processo de socialização legal em contextos e realidades distintas.

Diante disso, este artigo apresenta o campo da socialização legal para o público brasileiro a partir de dois movimentos. Primeiramente, uma exposição de revisão da literatura, destacando as abordagens tradicionais e os estudos recentes que se esforçam em explicar a formulação de crenças e atitudes legais, o comportamento de quebras de regras, a legitimidade das autoridades, o cinismo legal, a relação entre coerção e consentimento, entre outros. Em seguida, apontamos alguns desafios de pesquisa que possam contribuir para o desenvolvimento dessa área do conhecimento levando em consideração a realidade das crianças e adolescentes brasileiros. Evidentemente esses tópicos não esgotam as possibilidades de compreensão do tema, mas servem para dar uma ideia geral acerca da socialização legal.

\section{AS ABORDAGENS TRADICIONAIS: COGNITIVISMO E APRENDIZAGEM SOCIAL}

Os primeiros esforços em compreender o processo de socialização legal enfatizaram o desenvolvimento da capacidade de raciocínio do indivíduo sobre assuntos relacionados às instituições em geral e ao mundo legal. Trata-se de duas abordagens distintas: em primeiro lugar, a cognitivista, apoiada nas ideias do desenvolvimento humano do epistemólogo suíço Jean Piaget; e, em segundo lugar, a perspectiva da aprendizagem social, que explica o fenômeno do raciocínio a partir da filosofia do behaviorismo radical do psicólogo norte-americano Burrhus Skinner.

Segundo a abordagem cognitivista, o desenvolvimento mental do indivíduo é um processo contínuo de construção de estruturas cognitivas, cada vez mais complexas, que organizam o pensamento em busca de equilíbrio, uma adaptação do sujeito à realidade na qual está inserido. Esse processo pode ser categorizado em estágios, cuja ordem de sucessão é invariável e para o qual a maturação das estruturas é condição necessária, mas não suficiente. Assim, a passagem do primeiro estágio ao último ocorre pela progressão da maturação cognitiva do 
sujeito (guiada pelo desenvolvimento biológico) e pelas interferências culturais, que também exercem influência sobre essa evolução (Piaget; InHELdER, 1978).

Nessa perspectiva, os primeiros estudos de socialização legal destacaram os estágios invariáveis de desenvolvimento do raciocínio moral e legal. As estruturas cognitivas permitiriam a formulação de raciocínios através dos quais os indivíduos dariam sentido ao mundo social, interpretariam e se posicionariam em relação ao papel das leis.

Kohlberg e Kramer (1969) investigaram como as crianças elaboram e desenvolvem esses raciocínios. Para os autores, o raciocínio moral forneceria as bases sobre as quais as pessoas definiriam seu comportamento em sociedade. Isso significa que os julgamentos morais podem variar ao longo do tempo seguindo estágios biologicamente sequenciais conforme os indivíduos amadurecem em suas capacidades cognitivas. Cada estágio reflete o nível de julgamento individual em relação às convenções sociais.

São três os estágios descritos pelos autores. No primeiro, chamado de pré-convencional, os indivíduos, marcadamente egocêntricos e individualistas, concebem o certo e o errado de forma pragmática e instrumental. Os julgamentos e decisões nas relações com o mundo social estão fundamentados pela satisfação das necessidades pessoais.

No segundo estágio, convencional, os indivíduos estão abertos a sacrificar os interesses pessoais em nome de expectativas interpessoais e normas coletivas. Portanto, nesse estágio torna-se possível ao indivíduo apoiar as normas, as regras sociais, as leis e as autoridades.

Por fim, é no estágio pós-convencional que os indivíduos interpõem questões complexas entre seus julgamentos e compromissos com a ordem. Nesse estágio, os indivíduos passam a julgar as bases do contrato social seguindo princípios impessoais e universais. Daí ser possível ao indivíduo desenvolver julgamentos com base moral e racional das convenções sociais, tornando-se capaz, por exemplo, de cogitar mudanças nas leis e de questionar as autoridades.

Segundo Tapp e Kohlberg (1971), o nível convencional é o padrão para a maioria das pessoas em diferentes sociedades, e apenas uma minoria alcança o nível pós-convencional. Os autores acreditam que isso ocorre porque, apesar de seguir essa lógica sequencial-maturacional, o estímulo do ambiente é fundamental para o indivíduo atingir o estágio final do raciocínio moral, ou seja, é necessário que haja aprendizagem. Essa estimulação deve acontecer por meio de oportunidades de adoção de papel (role-taking opportunities), que são situações nas quais o indivíduo pode analisar diversos pontos de vista a partir de diferentes argumentos e posições. 
Sinteticamente, as oportunidades de adoção de papel tendem a gerar nos indivíduos maior independência e compliance (disposição em obedecer e agir de acordo com as leis) do que atividades não críticas e automáticas, pois expandem as capacidades humanas de diferenciar, integrar e contemplar diferentes pontos de vista. Essa expansão culmina no aperfeiçoamento individual dos sensos de dever, justiça e compreensão das leis (CoHn et al., 2010).

Os agentes socializadores assumem papel fundamental de acordo com essa lógica, visto que são eles que devem estimular o desenvolvimento de crianças e adolescentes através das oportunidades de adoção de papel. Ressalta-se a importância desses agentes, pois a depender da qualidade da estimulação o desenvolvimento moral tende a ser acelerado, retroagido ou até mesmo inibido.

Considerando que o sistema legal está entrelaçado aos princípios morais de uma sociedade, entende-se que o desenvolvimento moral e o legal estão correlacionados. Com esse movimento, Tapp e Kohlberg (1971) direcionaram o modelo de desenvolvimento moral de Kohlberg e Kramer (1969) aos processos de socialização em contexto legal.

Os resultados de Tapp e Kohlberg (1971) demonstraram que os sujeitos no estágio pré-convencional possuem a tendência somente de obedecer às regras (rule-obeying perspective), no convencional seguem a perspectiva de manutenção das regras (rule-maintaining perspective), e no pós-convencional possuem a capacidade de criação de regras (rule-making perspective).

Em geral, indivíduos nos níveis pré-convencional e convencional orientam-se primariamente por regras e valores fixos da sociedade em termos irrefletidos de certo e errado. Os primeiros são mais voltados para as possíveis consequências de seus atos, ao passo que os segundos estão orientados, principalmente, para a manutenção da ordem e do bem-estar social. Eles reconhecem a possibilidade de conflito entre o que é racionalmente certo para o indivíduo e o que é racionalmente certo para a sociedade. Por isso que os indivíduos com perspectiva pós-convencional seriam capazes de considerar viável a possibilidade de alterar as leis (TAPP; KoHLBERG, 1971).

Apoiadas nessa abordagem, Levine e Tapp (1974) construíram o chamado modelo cognitivo-interacional de raciocínio legal, em que os níveis cognitivos não são tão delimitados como no modelo anterior. Para as autoras, existe uma relação dialética entre os estágios em que as pessoas se encontram, distribuídos parte em seu nível dominante (cerca de 50\% das ideias), parte em seu nível anterior e parte no nível a ser alcançado, mas ainda não cristalizado. Dessa maneira, nenhum 
indivíduo estará totalmente em apenas um dos níveis de raciocínio legal, o que quebra com a lógica sequencial de estágios invariáveis.

Segundo as autoras, a dialética entre os níveis possibilita a mudança de estágios através da aprendizagem. A mudança ocorre quando o indivíduo está em situação de conflito, debatendo-se internamente na busca pela resolução de algum problema. Nesse momento, as estruturas cognitivas do indivíduo encontram-se em desequilíbrio, em estado de comparação e acomodação de novas e velhas informações presentes nos níveis posteriores ou inferiores de raciocínio legal. É precisamente por esse conflito de ideias de níveis diferentes que as estruturas são estimuladas para uma "evolução cognitiva estável e integrada" (LEvine; TAPP, 1974, p.166).

Esse modelo reforça a ideia de que a função dos agentes socializadores é a de prover oportunidades para que os indivíduos possam assumir papéis na sociedade. As autoras acreditam que somente as experiências sociais seriam capazes de estimular a evolução cognitiva por meio do desequilíbrio de suas estruturas para o nível pós-convencional.

Já a abordagem da aprendizagem social difere do modelo cognitivista por ter como premissa a concepção de que a aprendizagem de comportamentos normativos é determinada por fatores externos ao indivíduo. Isso significa que os diversos estímulos presentes no ambiente em que o sujeito está inserido condicionam suas atitudes e comportamentos (Conn; Whiтe, 1990).

Segundo Skinner (1938), existem dois tipos de aprendizagem. O primeiro tipo, chamado de condicionamento respondente, parte do entendimento de que existem certas reações inatas ao organismo que acontecem de acordo com determinado estímulo ambiental que as antecedem. $\mathrm{O}$ argumento é que, se o estímulo antecedente à reação for apresentado ao sujeito ao mesmo tempo que um outro estímulo qualquer, após algumas repetições desse experimento o indivíduo aprenderá a reagir na presença do novo estímulo.

O segundo tipo, o condicionamento operante, parte do pressuposto de que certos comportamentos emitidos por um organismo geram alguma consequência no ambiente. Dessa maneira, a qualidade e a recorrência da consequência aumentam a probabilidade de repetição de determinado comportamento no futuro.

Justamente por prover a capacidade de aprendizado de novos comportamentos, o condicionamento operante é entendido como conceito chave na aplicação da análise do comportamento à socialização legal. Nesse sentido, dois modelos de condicionamento operante foram elaborados: o da internalização e o da aprendizagem observacional. 
O modelo da internalização se refere ao processo de aprendizagem pelo qual um padrão contínuo de consequências resulta na adoção do comportamento que as produziu como exemplo a ser seguido, até mesmo sem a presença das influências externas que o reforçaram (ARonfreEd, 1968). Desse modo, por meio da internalização, o indivíduo adquire os modus operandi a ponto de não mais necessitar de controles externos.

O modelo da aprendizagem observacional descreve a instauração do comportamento no indivíduo através da imitação de padrões seguidos de estratégias de reforçamento (BANDURA, 1969). É muito comum perceber em crianças e adolescentes, que convivem juntos muito tempo, comportamentos similares. Isso ocorre porque, após o sujeito repetir certos comportamentos, recebe como consequência a aprovação do outro como elemento reforçador.

A teoria da aprendizagem social trata-se de uma importante contribuição ao campo da socialização legal no que concerne aos efeitos que os estímulos ambientais têm na aprendizagem dos indivíduos. Entretanto, segundo Cohn e White (1990), sua aplicabilidade ao universo social é discutível. Na obra das autoras, que compara as duas abordagens (cognitivista e aprendizagem social), discute-se a falta de poder de previsão, ao longo do tempo, do condicionamento operante em um ambiente multifacetado e não controlado.

A transferência de comportamentos aprendidos de um contexto social ao outro inevitavelmente gera diferenças no padrão de consequências obtidas pelo sujeito. Isso introduz ambiguidades no processo de análise das contingências desse comportamento que o condicionamento operante não consegue abarcar em seu modelo estrutural. Assim, as autoras concluem que a teoria cognitivista baseada no raciocínio legal é a abordagem mais adequada para analisar o processo de socialização legal.

O modelo tradicional de socialização legal, como vimos, centrava-se em explicar a relação entre o raciocínio moral e o comportamento. Diante disso, salienta-se a relevância do Laboratório de Socialização Legal (Legal Socialization Laboratory) da Universidade de New Hampshire, nos Estados Unidos, coordenado pela psicóloga social Ellen Cohn. Esse centro foi responsável pela transição entre as teorias marcadas pelo cognitivismo e o behaviorismo para os estudos que consideram a legitimidade e a justiça procedimental como elementos explicativos da socialização legal. O laboratório notabilizou-se ao investigar os fatores que geram comportamentos de violação de regras, o desenvolvimento de noções normativas, além do papel da legitimidade e do cinismo legal como mediadores de atitudes e de comportamentos em relação às leis. 
Os estudos realizados no laboratório de New Hampshire avançam nessa problemática e propõem um modelo integrado de socialização legal. $\mathrm{O}$ argumento principal desse modelo é que as relações com as autoridades medeiam as atitudes em relação às leis, contribuem para a internalização de noções normativas e encorajam ou não os comportamentos de quebra de regra, além de considerar os fatores situacionais da justiça procedimental no processo de socialização.

Pode-se dizer que o laboratório preencheu uma lacuna importante nos estudos sobre adolescência. Em geral, pesquisas sobre legitimidade ejustiça procedimental são realizadas com adultos. Ocorre que o adulto já possui longo histórico de interações com figuras de autoridade e conhecimentos relativamente consolidados sobre as leis que regulam a vida em sociedade. Como demonstra a literatura especializada (TYler, 1990; TYleR; JACKSON, 2014), as decisões individuais em obedecer e colaborar com as normas e as leis são baseadas nas crenças construídas ao longo de toda a vida por meio de contatos com as autoridades.

No entanto, pesquisas com adultos, além de ignorar a história pregressa de interações com autoridades e instituições, ainda negligenciam outras figuras de autoridade reconhecidamente importantes na conformação da obediência às leis. De um lado, as análises se restringem a contextos legais de relação entre indivíduos e autoridades, como contatos com a polícia e o sistema de justiça. Por outro lado, evidências indicam que figuras de autoridade não legais são tão relevantes quanto as autoridades públicas na construção da legitimidade e da confiança nas instituições; dentre elas, destacam-se os pais, os professores e os amigos. Assim, as experiências que os indivíduos têm com figuras de autoridade (legais e não legais) desde a infância são determinantes na compreensão das leis, tal como apontam os trabalhos de Ellen Cohn e demais pesquisadores vinculados ao Laboratório de Socialização Legal (CoHn; White, 1990; CoHn; Modecki, 2008; CoHn et al., 2010; JELEniewisk, 2014; Trinkner; CoHn, 2014).

\section{OS ESTUDOS RECENTES: LEGITIMIDADE E JUSTIÇA PROCEDIMENTAL}

Os estudos recentes extrapolam as abordagens tradicionais, expostas acima, e investigam não apenas como as pessoas se comportam frente às regras, mas também o que contribui para a construção da legitimidade das autoridades e das instituições. E o elemento central encontra-se na teoria da justiça procedimental.

O modelo de justiça procedimental, desenvolvido pelo psicólogo social e criminalista norte-americano Tom Tyler, consiste na observação dos procedimentos executados pelos agentes públicos ao lidar, direta ou indiretamente, com os cidadãos. Os três elementos fundamentais para a compreensão da noção de justiça 
procedimental são voz, respeito e equidade (voz ativa dos indivíduos envolvidos, tratamento respeitoso e digno por parte das autoridades, equidade nas decisões dos agentes). De acordo com esse modelo, os procedimentos adotados nas tomadas de decisão e o tratamento dos cidadãos por parte das autoridades nos encontros cotidianos são fundamentais para constituir no indivíduo a ideia de que aquelas autoridades e instituições são justas, necessárias e, consequentemente, têm o direito de exercer o poder legitimamente (TYLER, 1988).

Segundo o autor, a autoridade legítima é aquela que os cidadãos consideram adequada e necessária em termos normativos, que representa os valores da democracia e por isso deve ser obedecida. Legitimar uma autoridade seria, portanto, um dos caminhos para a obediência consentida e a cooperação com as leis (TYLER, 2006). Assim, as relações entre os indivíduos e as figuras de autoridade têm papel vital no processo de socialização legal.

A qualidade dessas experiências influencia substancialmente o modo como as pessoas lidam com as regras e as leis. A depender da maneira como a autoridade conduz suas ações e dos procedimentos adotados pode-se gerar legitimidade e confiança, de um lado, ou cinismo legal e comportamento de quebra de regras, de outro (FAgan; Tyler, 2005; TRINKNER; COHN, 2014).

Piquero et al. (2005) estão entre os primeiros a testar o modelo da justiça procedimental no campo da socialização legal com adolescentes, buscando aí pistas sobre as relações dos indivíduos com as autoridades. As preocupações principais dos autores giraram em torno de duas questões: a atribuição de legitimidade às instituições pelos jovens e o nível de cinismo legal diante das leis.

Para os autores, as experiências que os adolescentes têm com as autoridades moldam suas percepções e influenciam os comportamentos futuros dos indivíduos. Trata-se, acima de tudo, de um processo relacional que pode apontar para duas direções opostas: a da legitimidade, entendida como sentimento de obrigação em obedecer às decisões das autoridades, e a do cinismo legal, como crença de que transgredir uma lei é aceitável e razoável.

Em estudo realizado com jovens em dois bairros de perfis sociodemográficos distintos na cidade de Nova York, Fagan e Tyler (2005) verificaram que as abordagens policiais possuíam padrões diferentes a depender do público atingido. No bairro mais pobre, e com população majoritariamente negra, a atuação policial não respeitava os princípios da justiça procedimental e levava os moradores a não legitimarem as instituições. Os autores descobriram que quanto maior o número de detenções menor o nível de legitimidade, e que havia forte correlação entre minorias raciais e altos índices de cinismo legal. Além disso, observou-se que os 
indivíduos abordados pela polícia possuíam visões mais negativas sobre as autoridades e instituições do que aqueles que não tiveram contato.

Em outro estudo, Tyler et al. (2014) encontraram maiores taxas de comportamento criminal e menor propensão em cooperar com a polícia, e consequentemente com o sistema de justiça, entre aqueles que legitimavam menos a polícia. Os indivíduos abordados pela polícia atribuíam menor legitimidade do que aqueles que nunca tiveram contato direto com a instituição. Os que avaliaram negativamente as abordagens policiais, considerando-as intrusivas e injustas, legitimaram menos a instituição como um todo. Em dois trabalhos distintos, Trinkner (2012) e Trinkner e Cohn (2014) observaram que o tratamento justo é um bom preditivo da avaliação de legitimidade das autoridades por parte dos adolescentes.

Esses estudos têm em comum a descoberta de que os contatos cotidianos com as autoridades legais são vistos como momentos de aprendizado a respeito das próprias autoridades e das leis. Daí a importância de as autoridades adotarem procedimentos justos nas abordagens; caso contrário, transmitem aos indivíduos mensagens errôneas e negativas de suas figuras, das instituições que representam e de suas ações, que podem ser reconhecidas como injustas. O impacto negativo não ocorre somente na legitimidade atribuída às instituições, mas também na obediência às regras e leis e na disposição em cooperar com as autoridades.

Outros autores realçam as mensagens que o sistema de justiça transmite para os indivíduos durante as situações de contato. Para Justice e Meares (2014), o sistema de justiça criminal pode ensinar aos cidadãos noções de leis e de cidadania. Entretanto, ao ser seletivo, o sistema envia mensagens conflitantes que reduzem sua legitimidade e fazem com que os indivíduos deixem de apoiar as instituições. Nessa mesma linha, Slocum et al. (2015) enfatizam que os contatos involuntários com a polícia têm impactos negativos no comportamento dos adolescentes, na medida em que a percepção de injustiça faz com que os adolescentes apoiem o uso da violência nas resoluções de conflito do dia a dia.

Ainda sob a perspectiva da justiça procedimental, estudos destacam que não apenas as autoridades legais, como a polícia e o sistema de justiça, são capazes de ensinar os cidadãos e, principalmente, os jovens a respeito de regras e leis, mas também as autoridades da esfera não legal, como os pais e os professores, são responsáveis pela transmissão de valores que formam noções legais. Trinkner e Cohn (2014) testaram o modelo de justiça procedimental para três figuras de autoridade distintas: pais, professores e policiais. Em todos esses contextos, os resultados indicaram que a adoção de procedimentos justos pelas figuras de autoridade é fonte de fortalecimento da legitimidade e de redução do cinismo dos 
adolescentes em relação às leis. Com isso, a combinação de maior legitimidade $\mathrm{e}$ de menor cinismo legal desencoraja os adolescentes a violar as leis.

A importância das autoridades não legais na socialização também foi avaliada por pesquisas que consideram outras fontes de legitimidade para além da justiça procedimental. Trinkner et al. (2012) demonstraram como os estilos parentais (autoritário, autoritativo e permissivo) podem influenciar o comportamento de quebra de regras dos filhos. Os autores ressaltam que o tratamento dos pais em relação aos filhos e o tipo de exigências feitas no dia a dia familiar impactam na disposição dos jovens em legitimar e obedecer às autoridades.

Outros estudos observaram que as autoridades têm limites circunscritos em domínios sobre os quais podem exercer o poder e controlar os comportamentos. Darling et al. (2005; 2008) observaram que, por um lado, os filhos tendem a não obedecer aos pais quando entendem que determinadas regras avançam sobre o domínio pessoal. Nesses casos, os pais não têm direito de colocar regras para ditar comportamentos, mesmo que o procedimento seja justo e o tratamento respeitoso. Por outro lado, se as regras se enquadram em situações que os filhos acreditam que os pais têm o direito de exercer o poder da autoridade (como situações de segurança pessoal), então prevalece a obrigação em obedecer.

Milnitsky-Sapiro et al. (2006) também analisaram as perspectivas de pré-adolescentes e adolescentes a respeito das áreas em que os pais têm autoridade para tomar decisões. Além das diferenças relacionadas à faixa etária e ao gênero, as autoras observaram que, no caso da autoridade parental, o limite da sua ação está relacionado à busca dos adolescentes por autonomia. Em geral, os entrevistados achavam que, em caso de discordância, os pais deveriam controlar os filhos nas situações em que considerassem o assunto como parte da responsabilidade parental. Porém, ao avaliar que a situação dizia respeito a decisão pessoal, a autoridade dos pais encontrava resistência, de modo que desobedecê-los se tornava aceito e correto para os adolescentes.

Associada a essa discussão, alguns pesquisadores destacam os limites impostos às autoridades e seus impactos na avaliação de legitimidade da autoridade. Saarikkomäki (2015) analisou narrativas de jovens a respeito de abordagens policiais e de seguranças privados para medir o nível de justiça procedimental desses agentes. Usando situações fictícias, e as próprias experiências dos participantes, a pesquisadora confirmou a hipótese da justiça procedimental como elemento central de reconhecimento da legitimidade das autoridades. Além disso, descobriu que os jovens entendem que as funções dos agentes, por vezes, exigem o uso da força, embora apontem restrições, demonstrando que é possível legitimar uma 
abordagem em que haja o uso da força desde que respeite os limites impostos às autoridades de acordo com ideais normativos e os valores partilhados de respeito e de cidadania.

Segundo Laupa (1991), existem três atributos na visão de crianças e adolescentes ao avaliar uma autoridade: o status de adulto, o acúmulo de conhecimento e a posição social. A autora testa o grau em que as crianças conseguem distinguir esses três critérios ao decidir sobre a legitimidade da autoridade (definida como o direito de tomar decisão) e sobre o dever que a criança sente de obedecer essa autoridade. Enquanto as justificativas para a legitimidade se baseiam nas características da autoridade (a idade, o conhecimento e a posição social), as justificativas para obedecer referem-se à ação em si, ao tipo de regra imposta e à possibilidade de punição oriunda dos indivíduos com posição social.

Em outro estudo, Laupa e Turiel (1993) analisaram os limites que as crianças colocam aos professores e aos dirigentes escolares. As autoras consideram que as crianças julgam essas figuras pelo contexto. Dessa forma, haveria situações em que a autoridade não teria poder nenhum, assim como certas decisões estariam fora do escopo de sua atuação. O exemplo utilizado no artigo demonstra que as crianças reconheceram a autoridade do diretor no contexto escolar: em atividade no parque, a autoridade do diretor só era reconhecida com relação à regra estipulada: proibir brigar, era aceitável, mas proibir de jogar bola, não. Assim, o limite da autoridade também é flexível, a depender do domínio envolvido.

À medida que o campo de estudos se consolida na literatura internacional, surgem novos desafios para compreender o processo de socialização legal em contextos sociais heterogêneos. Dentre eles, destacamos ao menos duas tendências.

A primeira compreende as pesquisas que avaliam variações da socialização legal de acordo com diferentes grupos sociais, como imigrantes e membros de grupos étnico-raciais. Em estudo com jovens em conflito com a lei, Piquero et al. (2014) notaram que o cinismo e o comportamento de quebra de regras são mais presentes entre os imigrantes de segunda geração do que os de primeira geração nos Estados Unidos. Para os autores, conforme os adolescentes imigrantes se integram à sociedade norte-americana, torna-se mais difícil o monitoramento por parte dos pais (Piquero et al., 2014, p. 16).

Em outro trabalho, Fine e Cauffman (2015) desenvolveram um dos primeiros estudos a considerar a variação da socialização legal em razão dos grupos raciais. Os resultados demonstraram que a probabilidade de reincidência era menor com o passar do tempo, independente do grupo. Contudo, enfatizaram que as chances de ser pego pela polícia eram maiores para jovens negros do que brancos e latinos. 
Para as autoras, isso representa forte indício de viés racial no sistema de justiça dos Estados Unidos.

Em menor escala, há uma segunda tendência reunindo comparações transnacionais e estudos focalizando questões sobre socialização legal em outros contextos. Entre os estudos comparativos, destaca-se o trabalho de Darling et al. (2005). As autoras demonstraram como adolescentes do Chile, Filipinas e Estados Unidos definem de maneira distinta os domínios legítimos da autoridade parental, a depender dos aspectos culturais que influenciam essa relação. Nessa mesma perspectiva, o já citado trabalho de Milnitsky-Sapiro et al. (2006) apresenta resultados similares em pesquisa com pré-adolescentes brasileiros da cidade de Porto Alegre (até onde sabemos, o único trabalho sobre um caso brasileiro). As autoras observaram que os filhos limitam a autoridade dos pais de acordo com o domínio que as regras atingem num movimento entre resistência e conquista da autonomia pelos adolescentes.

Observa-se, portanto, que o campo da socialização legal tem se expandido desde as teorias cognitivistas até as abordagens da justiça procedimental, com diversos estudos destacando novos temas relevantes para a compreensão dos elementos fundamentais do universo legal. Conforme a discussão é adensada, diferentes questões passam a integrar os problemas de investigação, como a inserção dos fatores socioculturais, questões étnicas e raciais, as formas de tratamento das autoridades e a imposição de limites de domínios nos quais as figuras de autoridade podem agir sobre os indivíduos.

\section{DESAFIOS DE PESQUISA: 0 ESTUDO DA SOCIALIZAÇÃO LEGAL NO BRASIL}

Por tudo isso exposto acima, o entendimento da socialização legal no contexto brasileiro traz novos desafios para o campo de investigação. Não é viável compreender efetivamente a construção da legitimidade e da confiança nas leis, nas autoridades e nas instituições sem levar em consideração as condições sociais que produzem os valores responsáveis pelas condutas dos indivíduos.

Evidentemente, há especificidades sociais, culturais e geracionais que marcam o desenrolar do processo de socialização legal nas diferentes sociedades. Desse modo, as lacunas que buscamos preencher consistem na exposição de três desafios de pesquisa sobre esse tema no Brasil. Embora os estudos estejam consolidados na literatura internacional, não há pesquisas dessa natureza realizadas no país, tornando os desafios ainda maiores.

O primeiro desafio é o de investigar como crianças e adolescentes desenvolvem compreensões sobre as leis e as autoridades em uma sociedade marcada 
por profundas desigualdades socioeconômicas. Ao mesmo tempo, as constantes violações dos direitos das crianças e dos adolescentes, a persistência de crimes violentos e a ausência de instituições encarregadas de colocar em prática políticas públicas de contenção social (saúde, educação, segurança, geração de emprego e renda, habitação) criam uma oportunidade singular de refinamento do conhecimento produzido nesse campo.

É preciso estabelecer as mediações necessárias para investigar como a violência, direta ou indireta, afeta o processo de socialização legal com implicações nas crenças e nas atitudes em relação às autoridades e instituições. E o estudo da socialização legal torna-se elemento chave para compreender o impacto da criminalidade e das violações dos direitos humanos na formação de atitudes voltadas às normas, às leis e às autoridades com consequências diretas na qualidade de vida democrática.

Conforme exposto anteriormente, a infância e a adolescência são fases especialmente importantes no processo de socialização legal, uma vez que nesse período da vida os contatos com o mundo legal tornam-se mais frequentes. Diante disso, o segundo desafio consiste em definir um recorte etário apropriado para investigar os determinantes do processo de construção de legitimidade e de confiança nas autoridades e nas instituições do ponto de vista dos adolescentes brasileiros.

Por mais variadas que possam ser as abordagens teóricas e metodológicas, o desenvolvimento cognitivo é ainda uma variável fundamental na socialização legal. Assim, o enfoque na pré-adolescência, mais especificamente a faixa etária entre 11 e 15 anos, centra-se ao menos em três condições: i.) conforme literatura mobilizada ao longo do artigo, a passagem da infância para a adolescência é uma fase de reorganização da estrutura cognitiva do indivíduo voltada ao pensamento complexo. Trata-se de um período privilegiado para observar as mudanças qualitativas e quantitativas das estruturas cognitivas que elaboram o raciocínio legal; ii.) é no início da adolescência que os primeiros comportamentos significativos de transgressão às regras se manifestam, podendo impactar de forma duradoura na vida dos indivíduos por meio de atitudes antissociais e de comportamentos de risco; iii.) torna-se fundamental observar a transição da esfera doméstica para a esfera pública, especialmente os primeiros contatos com as autoridades para além da família, como a escola, a vizinhança, a polícia e o sistema legal, pois essas experiências impactam na vida adulta.

Por fim, o terceiro desafio gira em torno da construção conceitual de instrumentos de pesquisa capazes de captar as particularidades e os processos de transformações que ocorrem nessa parcela da população. 
Em contexto marcado por desigualdades sociais e violações de direitos fundamentais, esse desafio torna-se ainda maior na medida em que os parâmetros disponíveis para pesquisa foram desenhados e aplicados majoritariamente em outros países (sobretudo nos Estados Unidos). Por conta disso, é necessária uma aproximação ao universo simbólico (linguagens e concepções) das crianças e dos adolescentes brasileiros para abordar de maneira apropriada os temas que envolvem a elaboração de noções sobre regras e leis, os mecanismos que compõem a socialização legal, o peso da justiça procedimental na atribuição de legitimidade das autoridades, além da influência que a exposição à violência exerce na confiança às instituições.

A ausência de estudos sobre socialização legal no Brasil, todavia, não deve ser entendida como desencorajadora por parte dos pesquisadores. Pelo contrário, há inúmeras razões para compreender o modo pelo qual crianças e adolescentes formam os princípios básicos acerca do sistema legal. Observar a socialização legal não é acreditar que os indivíduos devam obedecer às leis cegamente, mas pensar na formação de cidadãos que possam reconhecer o momento correto de questionar criticamente as regras e as leis que consideram injustas. Afinal, há certas situações em que desobedecer determinada lei pode ser a coisa certa a se fazer. E os posicionamentos críticos são vitais para a manutenção do sistema legal em sociedades democráticas.

\section{CONSIDERAÇ̃̃ES FINAIS}

O Brasil inegavelmente passou por profundas transformações econômicas e sociais nas últimas três décadas. A principal delas foi a transição democrática. Nesse período, algumas conquistas importantes de direitos foram obtidas, mas a consolidação de valores democráticos depende, em grande medida, da disposição dos indivíduos em obedecer às regras e às leis, além de cooperar de maneira consentida com as autoridades públicas e de participar das decisões do país.

Apesar das evidentes mudanças, a sociedade brasileira não se alterou estruturalmente e nem com a velocidade desejada. Houve avanços importantes de acesso ao consumo, mas ainda há muitos esforços para superar as persistentes desigualdades sociais, a baixa qualidade de vida (inclusive de vida democrática), o acesso desigual aos direitos fundamentais, as elevadas taxas de criminalidade e de violações da dignidade humana, que atingem especialmente as crianças e adolescentes do país.

As mudanças na sociedade brasileira devem acompanhar a interiorização dos valores democráticos na vida dos indivíduos. Ao longo do artigo, destacamos 
que o processo de socialização legal contribui para o desenvolvimento de noções voltadas à legitimidade e à confiança nas autoridades e nas instituições responsáveis por implementar as leis e as regras. E a maneira privilegiada de detectar os possíveis saltos qualitativos ao longo do tempo se dá por meio da realização de estudos de natureza longitudinal, a partir da análise dos contatos que as crianças e os adolescentes têm com as esferas legais e não legais como a família, a escola e o sistema de justiça.

Entende-se que a socialização legal contribui decisivamente para o desenvolvimento de atitudes orientadas para a democracia. Esse processo não inclui somente a interiorização unilateral das normas e a obediência acrítica das leis, mas a compreensão de que a disposição em cooperar com as autoridades está ligada aos valores e compromissos comuns da sociedade. Daí a ênfase na justiça procedimental, no modo como as autoridades agem em relação às pessoas. A postura dos pais, dos professores e das autoridades legais favorece, ou prejudica, a aquisição e o exercício dos valores democráticos.

Sabemos das dificuldades que o conhecimento acadêmico tem em equacionar os problemas sociais. Uma das saídas possíveis consiste em traduzir os conhecimentos produzidos em contribuições práticas e viáveis para o entendimento do universo legal dos indivíduos. Diante disso, a aposta na socialização legal, como processo relacional de interiorização dos valores voltados para a compreensão das regras e leis da sociedade, consiste em inverter o olhar dos adultos em relação às crianças e aos adolescentes para favorecer o desenvolvimento da legitimidade e da confiança nas instituições democráticas.

O maior desafio reside na inclusão das crianças e dos adolescentes como figuras centrais na elaboração de noções e valores que promovam a adoção de atitudes e comportamentos em conformidade com o mundo legal. É necessário ampliar o alcance do debate acerca do papel que esses indivíduos ocupam na sociedade brasileira para assegurar a consolidação da democracia no país. Trata-se de perceber essa importante parcela da população não como fonte de problemas e de delinquência juvenil, mas como potenciais agentes de transformação da sociedade.

\section{REFERÊNCIAS}

Aronfreed, J. Conduct and Conscience: The Socialization of Internalized Control Over Behavior. Oxford: Academic Press, 1968.

Bandura, A. "Social-Learning Theory of Identificatory Processes”. In: GOSLIN, D. (Org.), Handbook of Socialization Theory and Research. Chicago: Rand McNally, 1969. 
Coнn, E.; Whiтe, S. Legal Socialization. A Study of Norms and Rules. New York: SpringerVerlag, 1990.

Cohn, E.; Modecki, K. “Legal Socialization”. In: CUTLER, B. (Org.), Encyclopedia of Law and Psychology, vol. 2, 2008, p. 450-453.

Corn, E. et al. An Integrated Model of Legal and Moral Reasoning and Rule-Violating Behavior: The Role of Legal Attitudes. Law and Human Behavior, vol. 34, n. 4, p. 295-309, 2010.

DARLING, N. et al. Rules, Legitimacy of Parental Authority, and Obligation to Obey in Chile, the Philippines, and the United States. New Directions for Child and Adolescents Development, n. 108, Summer, 2005.

Individual Differences in Adolescents' Beliefs About the Legitimacy of Parental Authority and Their Own Obligation to Obey: A Longitudinal Investigation. Child Development, vol. 70, n. 4, p. 1103-1118, July/August, 2008.

FAGAN, J.; TYLER, T. Legal Socialization of Children and Adolescents. Social Justice Research, vol. 18, n. 3, p. 217-242, September, 2005.

Fine, A.; Cauffman, E. Race and Justice System Attitude Formation During the Transition to Adulthood. Journal of Developmental and Life-Course Criminology, vol 1, issue 4, p. 325-349, December 2015.

Jeleniewski, S. Expanding Legitimacy in the Procedural Justice Model of Legal Socialization: Trust, Obligation to Obey and Right to Make Rules. Dissert. University of New Hampshire, 2014.

Justice, B.; Meares, T. How the Criminal Justice System Educates Citizens. Annals, AAPSS, 651, January, 2014

Kohlberg, L.; Kramer, R. Continuities and Discontinuities in Childhood and Adult Moral Development. Human Development, vol. 12, n. 2, p. 93-120, 1969.

LaUPA, M. Children's Reasoning About Three Authority Attributes: Adult Status, Knowledge, and Social Position. Developmental Psychology, vol. 27, n. 2, p. 321-329, 1991.

LAUPA, M.; TurIEL, E. Children's Concepts of Authority and Social Contexts. Journal of Educational Psychology, vol. 85, n. 1, p. 191-197, 1993.

Levine, F; TAPp, J. Legal Socialization: Strategies for an Ethical Legality. Stanford Law Review, p. 1-72, 1974.

Milnitsky-SAPIRo, C. et al. Brazilian Adolescents' Conceptions of Autonomy and Parental Authority. Cognitive Development, vol. 21, p. 317-331, 2006.

Piaget, J.; Inhelder, B. A psicologia da criança. Rio de Janeiro: Difel, 1978.

Piquero, A. et al. Developmental Trajectories of Legal Socialization Among Serious Adolescents Offenders. J. Crim. Law Criminol., 1, 96(1), p. 267-298, September, 2005. 
. Longitudinal Patterns of Legal Socialization in First Generation Immigrants, Second Generation Immigrants, and Native Born Serious Youthful Offenders. Crime \& Delinquency, August 20, 2014.

SAarikкomäki, E. Perceptions of Procedural Justice Among Young People: Narratives of Fair Treatment in Young People's Stories of Police and Security Guard Interventions. British Journal of Criminology, 23, September, 2015.

Skinner, F. The Behavior of Organisms: An Experimental Analysis. New York: AppletonCentury Crofts, 1938.

Slocum, L. et al. The Importance of Being Satisfied. A Longitudinal Exploration of Police Contact, Procedural Injustice, and Subsequent Delinquency. Criminal Justice and Behavior, vol. 43, n. 1, 2015.

TAPP, J.; KoHLBERG, L. Developing Senses of Law and Legal Justice. Journal of Social Issues, vol. 27, n. 2, p. 65-91, 1971.

Trinkner, R. Testing the Procedural Justice Model of Legal Socialization: Expanding Beyond the Legal World. Dissert., University of New Hampshire, 2012.

Trinkner, R. et al. Don't Trust Anyone Over 30: Parental Legitimacy as a Mediator Between Parenting Style and Changes in Delinquent Behavior Over Time. Journal of Adolescence, 35, p. 119-132, 2012.

Trinkner, R.; Cohn, E. Putting the 'Social' Back in Legal Socialization: Procedural Justice, Legitimacy, and Cynicism in Legal and Nonlegal Authorities. Law and Human Behavior, vol. 38, n. 6, p. 206-617, 2014.

Trinkner, R.; Tyler, T. Legal Socialization: Coercion versus Consent in an Era of Mistrust. Annual Review of Law and Social Science, n. 12, p. 417-39, 2016.

Tyler, T. What is Procedural Justice?: Criteria used by Citizens to Assess the Fairness of Legal Procedures. Law \& Society Review, vol. 22, n. 1, p. 103-136, 1988. . Why People Obey the Law. New Haven: Yale University Press, 1990.

Psychological Perspectives on Legitimacy and Legitimation. Annu. Rev. Psychol., n. 57, p. 375-400, 2006.

Tyler, T. et al. Street Stops and Police Legitimacy: Teachable Moments in Young Urban Men's Legal Socialization. Journal of Empirical Legal Studies, vol. 11, issue 4, p. 751-785, December, 2014.

TYLeR, T.; JACKson, J. Popular Legitimacy and the Exercise of Legal Authority: Motivating Compliance, Cooperation, and Engagement. Psychology, Public Policy, and Law, vol. 20, n. 1, p. 78-95, 2014. 